\title{
Diurnal patterns of postfeeding larval dispersal in carrion blowflies (Diptera: Calliphoridae)
}

\author{
PETR KOČÁREK* \\ Department of Ecology, Palacký University, CZ-771 46 Olomouc, Czech Republic; e-mail: kocarek@email.cz
}

Key words. Diurnal activity, circadian rhythms, postfeeding dispersal, larvae, carrion, Calliphora vomitoria, Lucilia caesar, Diptera

\begin{abstract}
A study of the diurnal rhythms in the postfeeding dispersal of the larvae of two coexisting carrion blowfly species, Calliphora vomitoria and Lucilia caesar, from corpses was conducted in the field. Larvae of both species dispersed exclusively at night. The emigration of white coloured larvae is risky. By dispersing at night the larvae minimise interactions with diurnal and crepuscular predators.
\end{abstract}

\section{INTRODUCTION}

Blowflies (Calliphoridae) are the most significant group of arthropods in carrion decomposition and form a diverse and specialised community (Hanski, 1987). They are among the first insects to arrive at a corpse and their larvae (named maggots) make up the dominant part of the biomass.

Holdaway (1930), Fuller (1934) and Cragg (1955) found an array of different necrophagous fly species coexploiting mammalian carrion. These observations suggest an apparent contradiction to Gause' theory (Gause, 1964) that two species with identical niche requirements cannot coexist indefinitely. The various necrophagous species of flies did not treat the carcass as a homogeneous resource, but coexist because they were apparently able to specialise on different aspects of the food resource (Denno \& Cothran, 1975). Ives (1991) studied the influence of aggregation on the coexistence of carrion fly species and found that the intraspecific aggregations increased intraspecific competition and reduced interspecific competition. The competition between maggots of Calliphora vicina Robineau-Désvoidy, 1830 and Lucilia sericata (Meigen, 1826) in carrion was studied in detail by Smith \& Wall (1997).

Before pupation, the majority of blowfly maggots disperse from the corpse into the surroundings (Putman, 1983; Bassanezi et al., 1997). The maggots move on the soil surface over a distance of a few metres from the corpse and pupate in the soil; some maggots may disperse distances of 6-10 m (Green, 1951; Tessmer \& Meek, 1996). The timing of the larval wandering is controlled by a gated circadian rhythm (Richards et al., 1986); the response seems to be to light intensity rather than the changes in temperature and humidity characteristic of nighttime (Smith et al., 1981).

The diurnal patterns in the emigration of maggots from rat corpses was investigated in two coexisting blowfly species, $\mathrm{Cal}$ liphora vomitoria (L., 1758) and Lucilia caesar (L., 1758).

\section{MATERIALS AND METHODS}

The experiments were conducted in Suché Lazce, Czech Republic ( $49^{\circ} 54^{\prime \prime} \mathrm{N} ; 18^{\circ} 00^{\prime \prime} \mathrm{E}$ ). Grey laboratory rats (Rattus norvegicus Berk), typical of a small mammal, were used as bait. The fresh rat carcasses (weight 70-80 g) were put in traps, placed in a meadow and monitored during all the stages of decomposition in the autumn of 1997 (1st October - 10th November). The traps were equipped with an automatic sorting mechanism with a two hour catch period. Each trap consists of three basic parts: (1) an external metal case $(20 \mathrm{~cm}$ diameter) buried in the ground with the lip flush with the soil surface; (2) an internal part with 12 collecting vessels (filled with water solution of ethylene glycol) supported on a clock mechanism; (3) a basin with the bait. The larvae were removed from the collecting vessels and stored in alcohol. Some of the live maggots were separated and put into breeding vessels with soil to obtain adults. These adults were used to determine the species.

\section{RESULTS AND DISCUSSION}

During a decomposition a corpse passes through a number of distinct phases of decay, which may be distinguished in terms of a series of characteristic changes in its outward appearance (Putman, 1983). The emigration of blowfly maggots from a corpse characteristically occurs at the end of the most rapid stage of decomposition, named active decay (Reed, 1958) or butyric fermentation (Bornemissza, 1957). Due to competition for food and the influence of predators, blowfly maggots develop very fast and synchronously. Most of the maggots leave a corpse within a short period of several hours; the few remaining maggots represent the late-comers, and individuals parasitized by Hymenoptera (Peschke et al., 1987). In this study $94.6 \%$ of blowfly maggots emerged from the rat carcasses totally, the rest were found in the soil under the corpse. The process of carcass decomposition is illustrated by the daily loss in biomass in Fig. 1. Emigration of Lucilia caesar maggots from carcasses started on the 7th day after the exposure of the rats and lasted for 3 days (Fig. 1); the majority of maggots emigrated on the 8 th day $(79.2 \%)$. Emigration of Calliphora vomitoria started on the 9th day, lasted for 4 days (Fig. 1) and the majority emigrated on the 10th day $(72.9 \%)$.

The diurnal incidence of emigration in Calliphora vomitoria and Lucilia caesar is illustrated in Fig. 2. Maggots of both species emigrated exclusively at night. Most maggots were caught between 00-02 h in Lucilia caesar and between 04-06 h in Calliphora vomitoria. The occurrence of emigration by maggots during the day has been recorded by Schoenly (1983) in Texas, USA. He recorded small numbers emerging from the carcasses at night between $01-07 \mathrm{~h}$, the emergence continued into late morning. The species of maggot was not determined, but the dominant species caught as imagoes in this study was the calliphorid Cochliomyia macellaria (F.). That maggots disperse

\footnotetext{
* Present address: Koblovská 93, 71100 Ostrava 2, Czech Republic
} 


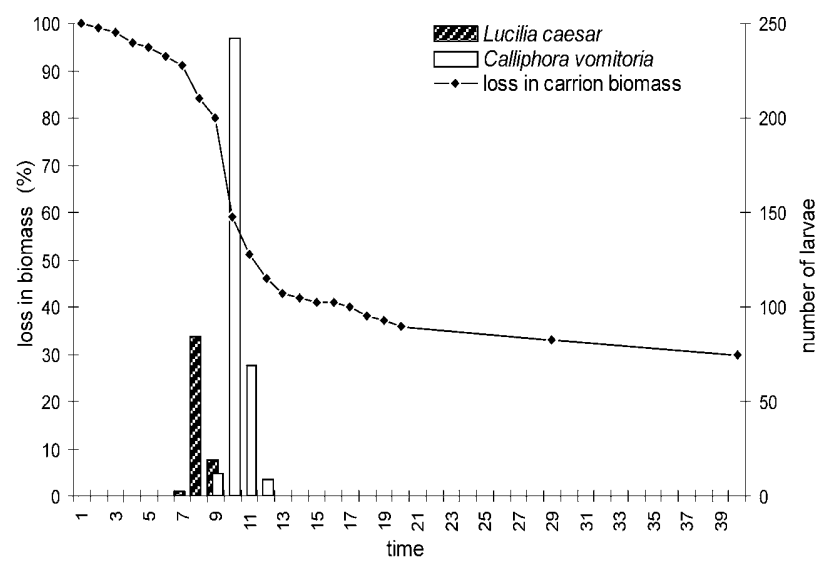

Fig. 1. Rate of carcass decomposition expressed as percentage of initial carcass weight against time (days) for which the carcass had been exposed. Columns show time and number of maggots of Lucilia caesar and Calliphora vomitoria that dispersed from the carcass.

from carrion late at night has been recorded for the sheep blowfly Lucilia cuprina (Wiedemann) by Smith et al. (1881) and the flesh-fly Sarcophaga argyrostoma (Robineau-Desvoidy) by Richard et al. (1986).

The emigration of white coloured maggots involves considerable risk. Once they leave the carrion, the maggots are exposed to predation by small insectivorous birds and mammals, and a variety of predatory insects (Putman, 1983; Roberts, 1984). Emigrating at night appears to be an adaptation to minimise predation by diurnal or crepuscular active predators (insectivorous birds, mammals, lizards and amphibians). The majority of insect predators show a diurnal or crepuscular activity (Kočárek, 1998), see Fig. 3.

During decomposition the body fluids from the corpse and the excrement (ammonium) from the maggots passes into the soil and destroys the underlying plants as well as the soil fauna (Bornemissza, 1957). The dispersal of maggots from carrion and away from the surrounding contaminated soil also reduces the risk of the larvae being adversely affected by toxic during pupas development.

A detailed knowledge of the emigration process is important for medicolegal forensic entomology (Catts \& Goff, 1992).

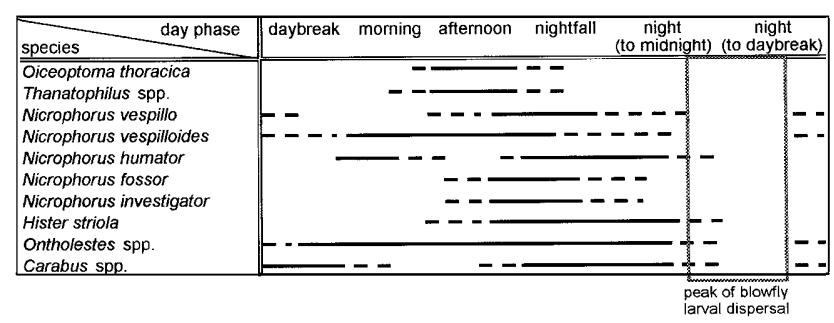

Fig. 3. Diurnal activity of some Coleopteran predators of the larvae of carrion blowflies recorded in the same locality during the decomposition of the rat carcasses (Kočárek, 1998) relative to the diurnal dispersal activity of the blowfly maggots.

ACKNOWLEDGEMENTS. I would like to thank F. Gregor (Brno, Czech Republic) for identifying the adults of Calliphoridae. The project was funded by Palacký University studentship No. 32503002/1997 and No. 32503007/1999.

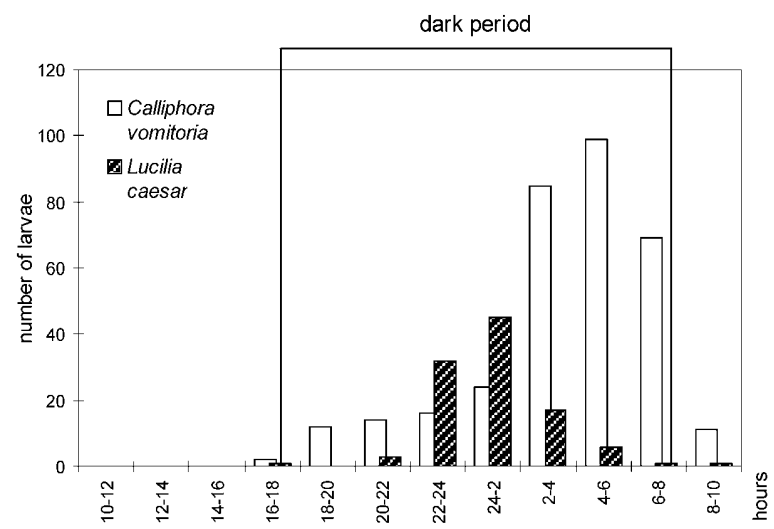

Fig. 2. Histogram showing diurnal dispersal activity of larvae of Lucilia caesar and Calliphora vomitoria from carrion.

\section{REFERENCES}

Bassanezi R.C., Leite M.B.F., Codoy W.A.C., Von Zuben C.J., Von Zuben F.J. \& ReIs S.F. 1997: Diffusion model applied to postfeeding larval dispersal in blowflies (Diptera: Calliphoridae). Mem. Inst. Oswaldo Cruz 92: 281-286.

BorNEMISSZA G.F. 1957: An analysis of arthropod succession in carrion and the effect of its decomposition on the soil fauna. Aust. J. Zool. 5: 1-12.

CATTS E.P. \& Goff M.L. 1992: Forensic entomology in criminal investigations. Annu. Rev. Entomol. 37: 253-272.

CragG J.B. 1955: The natural history of sheep blowflies in Britain. Ann. Appl. Biol. 42: 197-207.

Denno R.F. \& Cothran W.R. 1975: Niche relationships of a guild of necrophagous flies. Ann. Entomol. Soc. Am. 68: 741-754.

Fuller M.E. 1934: The insect inhabitants of carrion: a study in animal ecology. Council. Sci. Ind. Res. Australia Bull. 82: $1-63$.

Gause G.F. 1964: The Struggle for Coexistence. Reprinted from the 1934 edition. Hafner, New York, 163 pp.

Green A.A. 1951: The control of blowflies infesting slaughterhouses. I. Field observations of the habits of blowflies. Ann. Appl. Biol. 38: 475 pp.

HANSKI I. 1987: Carrion fly community dynamics: patchiness, seasonality and coexistence. Ecol. Entomol. 12: 257-266.

HoldawAy F.G. 1930: Field populations and natural control of Lucilia sericata. Nature (London) 126: 648-649.

IVES A.R. 1991: Aggregation and coexistence in a carrion fly community. Ecol. Monogr. 61: 75-94.

KoČÁREK P. 1998: Daily periodicities in arthropods visiting carrion. In Brunnhofer V. \& Soldán T. (eds): Book of Abstracts, VIth Europ. Congr. Entomol. (České Budějovice, August 23-29, 1998), p. 387.

Peschke K., Krapf D. \& Fuldner D. 1987: Ecological separation, functional relationships, and limiting resources in a carrion insect community. Zool. Jb. System. 114: 241-265.

Putman R.J. 1983: Carrion and Dung: the Decomposition of Animal Wastes. Edward Arnold, London, 62 pp.

REeD H.B. 1958: A study of dog carcass communities in Tennessee, with special reference to the insects. Am. Midl. Nat. 59: $213-245$.

Richards D.S., Saunders D.S., Egan V.M. \& Thomson R.C.K. 1986: The timing of larval wandering and puparium formation in the flesh-fly Sarcophaga argyrostoma. Physiol. Entomol. 11: 53-60. 
RoBerTs B. 1984: Photoperiodic regulation of prothoracicotropic hormone release in late larval, prepupal, and pupal stages of Sarcophaga bullata. Ciba Found. Symp. 104: $170-188$

SCHOENLY K. 1983: Microclimate observations and diel activities of certain carrion arthropods in Chihuahuan desert. N.Y. Entomol. Soc. 91: 342-347.

Smith P.H., Dallwitz K.G., Wardhaugh W.G. Vogt W.G. \& WoodBuRn T.L. 1981: Timing of larval exodus from sheep and carrion in the sheep blowfly, Lucilia cuprina. Entomol. Exp. Appl. 30: 157-162.

Sмith K.E. \& Wall R. 1997: Asymmetric competition between larvae of the blowflies Calliphora vicina and Lucilia sericata in carrion. Ecol. Entomol. 22: 468-474.

Tessmer J.W. \& Meek C.L. 1996: Dispersal and distribution of Calliphoridae (Diptera) immatures from animal carcasses in southern Louisiana. J. Med. Entomol. 33: 665-669.

Received January 20, 2000; revised March 30, 2000; accepted July 10, 2000 